\section{Utilization of Waste Plastic in Soil Backfill}

\section{Jihan Elsheikhidriss Ibrahim Eltayeb* and AbdElshakoor Awad Elkareem Elhindy}

Department of Chemical Engineering, University of Khartoum, Sudan

*Corresponding author: Eltayeb JEl, Department of Chemical Engineering, University of Khartoum, Sudan, Tel: 00249918000980; E-mail: jihanidris@hotmail.com Received date: August 05, 2018; Accepted date: August 25, 2018; Published date: September 03, 2018

Copyright: ( 2018 Eltayeb JEl, et al. This is an open-access article distributed under the terms of the Creative Commons Attribution License, which permits unrestricted use, distribution, and reproduction in any medium, provided the original author and source are credited.

\begin{abstract}
This study aims to use waste plastic Polyethylene Terephathalete (PET) in backfills in order to dispose of waste plastic firstly and improve the soil properties. Three types of soil samples have been investigated. The first one (sample A) was a mixture of clay and only one size (10 mm mesh) of PET plastic chips with different percentages $(1.5 \%, 3.0 \%, 4.5 \%$ and $6.0 \%)$ by weight. The second one (sample B) employed four different sizes of the waste plastic chips PET $(5.0,6.5,10.0$ and $12.5 \mathrm{~mm}$ mesh), and four different percentages $(1.5 \%, 3.0 \%, 4.5 \%$ and $6.0 \%)$ by weight. The third one (sample C) employed only one size $(10 \mathrm{~mm} \mathrm{mesh})$, and a percentage of (4.5\%) by weight of waste plastic. A total number of 16 tests were conducted for the second sample and five tests for the first sample, and two tests for the third sample. The laboratory tests adapted the California Bearing Ratio values (CBR) to determine the effect of plastic chips on the soil mixtures. For sample A the values of CBR decreased from 2.2 for pure soil to 2.1 when the amount of plastic added is $3 \%$ chips. For sample B the values of CBR increased to 1.63 and 1.56 when the amount of plastic added is $1.5 \%$ for (size 5 and $12.5 \mathrm{~mm}$ ) respectively. For $3 \%, 4.5 \%$ additions with (size $6.5 \mathrm{~mm}$ ) the CBR is 1.62 for both. No general trends are observed for the 23 tests conducted. The soil subgrade with PET did not increase soil strength. The reason may due to decrease of cohesion or to the results of the pure natural soil under consideration. The results showed that the addition of waste plastic did not improve the properties of soil. it cannot be used as an effective method in disposing of waste plastic materials as mentioned in the research hypothesis. However, the research recommends that more trials to be conducted using different shapes of plastic waste, and to use different types of binders.
\end{abstract}

Keywords: Plastic soil backfill; Polyethylene terephathalete; Plastic waste

\section{Introduction}

Plastics are the foundation of industry and modern lifestyles, also considered as light and robust, resistant to rust and corrosion, transparent and freely colorable, mass producible, excellent electrical and electronic properties, high heat-insulation efficiency, hygienic with a strong gas barrier [1]. All types of plastics are discarded after use which creates a huge amount of waste. The service life of plastic products ranges from 1-100 years vary according to properties of plastics types [2]. In many places plastic waste types are collected for recycling or reuse but unfortunately, the secondary markets for reclaimed types of plastic do not develop recycling programs. Hence it occupies a large proportion of garbage in the landfill. There are several methods for disposal of municipal and industrial plastic wastes, e.g., landfill, incinerations, material recycle. In recent year, waste plastics found a new use in soil stabilization.

\section{Literature Review}

Some countries use many methods to dispose plastic by adding them to the soil for reinforcement or landfill only, without influenced to environment. Some of researches papers in waste plastics are reviewed below:

Chen [3] prove that slender recycled plastic pins (RPPs) can be used to stabilize earthen slopes by driving the RPPs into the face of the slope to intercept the sliding surface and "pin" the slope. The RPPs will be subjected to lateral bending forces, and their ability to resist deformation will strongly influence the success of the RPPs for stabilizing slopes. Arrhenius modeling showed creep failure ranged from 50 to 3,900 years at field temperature and stress levels.

Choudhary et al. [4] demonstrated that waste plastics can be used as reinforcement and for this purpose a series of experimental study was carried out to investigate the CBR behavior of waste plastic strip reinforced soil. The effect of waste plastic strip content $(0.25 \%$ to $4.0 \%)$ and strip length on the CBR and secant modulus of strip reinforced soil addition of waste plastic strips of appropriate size and proportions in soil results in an appreciable increase in both the CBR and secant modulus.

Khane and Feroz [5] shows that use of waste plastic fibers in soil in an appropriate amount really aids in improving the strength of soil and also helps in modification of soil properties.

Sivakumar and Jaladurgamand [6] shown that for them combination of fly ash and plastic waste is very useful in unpaved roads, it is effective in improving the engineering properties of fly ash in terms of compressive strength, shear strength parameters, and CBR values. The shear strength increases with the increase in sample size.

Edil et al. [7] who utilization compressibility of recycled materials including bottom ash (BA), foundry slag (FSG), foundry sand (FSD), recycled asphalt pavement (RAP), recycled pavement material (RPM), recycled concrete aggregate (RCA), and recycled asphalt shingle (RAS) mixed with glacial outwash sand (GOS) was evaluated using onedimensional (1D) compression tests. Results showed that except RCA, compressibility of all the compacted recycled materials is higher than that of the compacted GOS. 
Citation: Eltayeb JEI, Awadelkareem A (2018) Utilization of Waste Plastic in Soil Backfill. J Environ Anal Chem 5: 246. doi: $10.4172 / 2380-2391.1000246$

Page 2 of 5

\section{Methodology}

\section{Materials}

Plastic wastes: PET water bottle wastes were collected from different places. The bottles were shredded by shredder machine, the shredded plastic materials were then sieved into four sizes of chips $(5,6.5,10$, $12.5 \mathrm{~mm}$ meshes). The average thickness is $0.2 \mathrm{~mm}$.

Soil: Soil samples from three locations in Khartoum state East Bahry, South Bahry and Algadarif state in Sudan.

Equipment: All experiments in this work were conducted at The Mechanical Soil Laboratory at University of Khartoum and Building and Road Researches Institute:

The equipment used was Set of standard sieves, Sieve shaker, Atterberg limits devices, Glass plate, Liquid limit device, Grooving tool, CBR Testing Machine, Beaker, Rammer, Manual Hammer, Standard mould of compaction, Drying Oven, Glass Bottle, Balance, Bowl, Mould, Moisture cans, Graduated cylinder, Mixing tools, Trowel, Sample splitter or riffle for dividing the samples, Loading machine, Soaking tank, Filter paper.

\section{Methods}

\section{Soil classification}

Classification is used in engineering and geology to describe the texture and grain size of a soil.

Based on percentages of gravel, sand, silt and clay, soil gradation curve, Consistency limits (plasticity index and liquid limit), water content.

\section{Compaction test}

The laboratory test generally used to obtain the maximum dry unit weight of compaction and the optimum moisture content is called the Proctor compaction test. These two are then used to utilization in CBR test according to British standard 1377, part 4, 1990.

\section{California Bearing Ratio (CBR)}

$\mathrm{CBR}$ is the ratio of force per unit area required to penetrate in to a soil mass with a circular plunger of $50 \mathrm{~mm}$ diameter at the rate of 1.25 $\mathrm{mm} / \mathrm{min}$. From the results of compaction tests (optimum moisture content and maximum dry density) soil moisture mixture was prepared the prepared samples are transferred to mould and compacted. The compacted soil is immersed in water for 4 day. The mould is then transferred to penetration device which determines the penetration distance against the load applied from the charts obtained the load applied to give penetration of 0.2 and 0.1 . The highest reading is used to calculated CBR value using British standard 1377, part 4, 1990.

\section{Results}

\section{Classification of soil}

Tests were carried out to determine the various properties of soil and results are tabulated in Table 1.

\begin{tabular}{|l|l|l|l|}
\hline Soil & Sample A & Sample B & Sample C \\
\hline Clay & $40.64 \%$ & $52.19 \%$ & $23 \%$ \\
\hline Silt & $23.36 \%$ & $28.48 \%$ & - \\
\hline Sand & $36 \%$ & $19.33 \%$ & $19 \%$ \\
\hline gravel & 0 & 0 & $58 \%$ \\
\hline Liquid limit (LL) & $54 \%$ & $65 \%$ & $23 \%$ \\
\hline Plastic limit (PL) & $24.10 \%$ & $20.60 \%$ & $15 \%$ \\
\hline Plasticity index (PI) & $29.90 \%$ & 44.4 & $8 \%$ \\
\hline
\end{tabular}

Table 1: Classification of soil.

\section{Standard Proctor test}

Figures 1-2 show the relationship between moisture content of the soil and dry density. From each Figures 1-10 the optimum moisture content is explained for highest (maximum) dry density the values are shown in Tables 2-4.

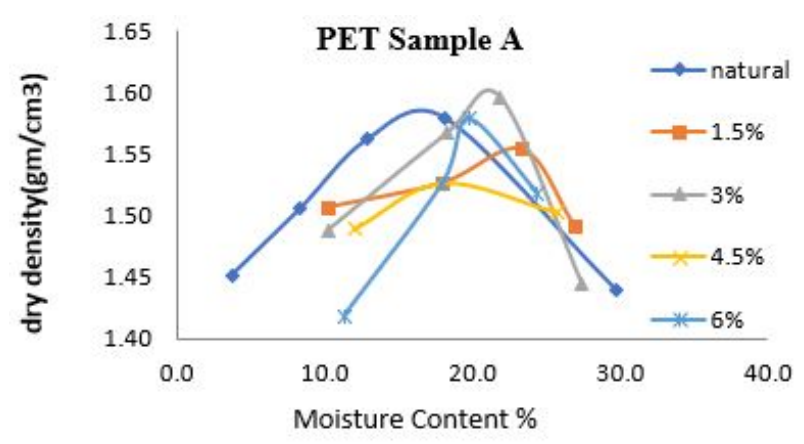

Figure 1: Compaction Test, Sample A, PET (10 mm Size).

\begin{tabular}{|l|l|l|}
\hline Percentage of PET in soil & $\begin{array}{l}\text { optimum moisture } \\
\text { content\% }\end{array}$ & $\begin{array}{l}\text { optimum dry density } \\
\left(\mathbf{g m} / \mathbf{c m}^{3}\right)\end{array}$ \\
\hline $0 \%$ & 18.12 & 1.58 \\
\hline $1.50 \%$ & 23.4 & 1.55 \\
\hline $3 \%$ & 21.96 & 1.6 \\
\hline $4.50 \%$ & 19.6 & 1.59 \\
\hline $6 \%$ & 20.2 & 1.58 \\
\hline minimum & 18.12 & 1.55 \\
\hline maximum & 23.4 & 1.6 \\
\hline
\end{tabular}

Table 2: Compaction Test, Sample A, Optimum Moisture Content and Maximum Dry Density Versus Percentage of PET (10 mm Size) in Soil. 
Citation: Eltayeb JEl, Awadelkareem A (2018) Utilization of Waste Plastic in Soil Backfill. J Environ Anal Chem 5: 246. doi:

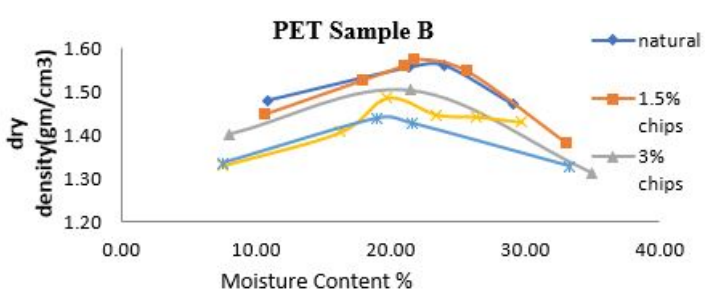

Figure 2: Compaction Test, Dry Density versus Moisture Content, Sample B.

\begin{tabular}{|l|l|l|}
\hline Percentage of PET in soil & $\begin{array}{l}\text { Optimum moisture } \\
\text { content\% }\end{array}$ & $\begin{array}{l}\text { Maximum dry density } \\
\left(\mathbf{g m} / \mathbf{c m}^{3} \mathbf{)}\right.\end{array}$ \\
\hline $0 \%$ & 23.6 & 1.57 \\
\hline $1.50 \%$ & 21.5 & 1.57 \\
\hline $3 \%$ & 20.5 & 1.5 \\
\hline $4.50 \%$ & 20 & 1.49 \\
\hline $6 \%$ & 19.1 & 1.44 \\
\hline minimum & 19.1 & 1.44 \\
\hline maximum & 23.6 & 1.57 \\
\hline
\end{tabular}

Table 3: Compaction Test, Sample B, Optimum Moisture Content and Maximum Dry Density versus Percentage of PET in Soil.

\begin{tabular}{|l|l|l|}
\hline Percentage of PET in soil & $\begin{array}{l}\text { Optimum moisture } \\
\text { content\% }\end{array}$ & $\begin{array}{l}\text { Maximum dry density } \\
\left(\mathbf{g m} / \mathbf{c m}^{3} \mathbf{)}\right.\end{array}$ \\
\hline $0 \%$ & 5.4 & 2.22 \\
\hline $4.50 \%$ & 4.3 & 1.51 \\
\hline
\end{tabular}

Table 4: Compaction Test, Sample B, Optimum Moisture Content and Maximum Dry Density versus Percentage of PET in Soil.

\section{CBR test}

Table 5 shows the values of CBR for different addition of PET for sample A soil. No general trend is observed but the maximum value is found at $4.5 \%$ addition of PET. On the other hand, Table 6 shows the values of CBR for sample B soil with different additions and different sizes of PET. Once again, no general trend for the values of CBR for different additions PET, but the maximum CBR is observed when $1.5 \%$ of $5 \mathrm{~mm}$ PET is added. Table 7 shows the values of CBR for one addition of PET (4.5\%) for sample (C) soil is observed decrease in the value of CBR.

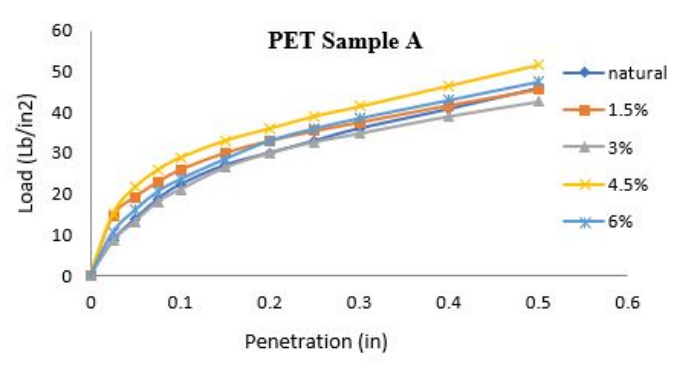

Figure 3: Sample A, Percentage of PET (10 mm), Penetration Versus Load.

\begin{tabular}{|l|l|l|l|l|l|l|l|}
\hline Percentage PET & $\mathbf{0} \%$ & $\mathbf{1 . 5 0} \%$ & $\mathbf{3} \%$ & $\mathbf{4 . 5 0} \%$ & $\mathbf{6 \%}$ & Minimum & Maximum \\
\hline CBR & 2.22 & 2.58 & 2.1 & 2.88 & 2.35 & 2.1 & 2.88 \\
\hline
\end{tabular}

Table 5: Different Percentage of PET (10 mm) Sample A in CBR.

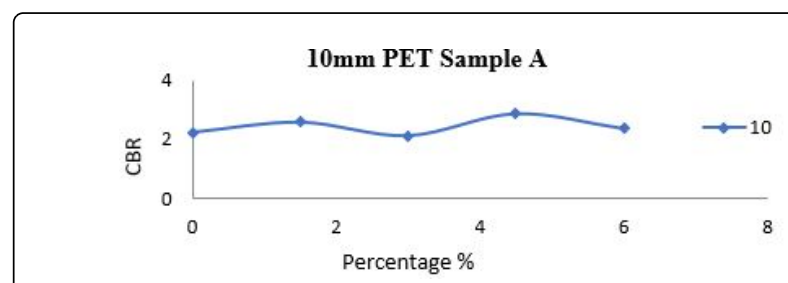

Figure 4: Percentage of (10 mm Size) PET versus CBR, Sample A.

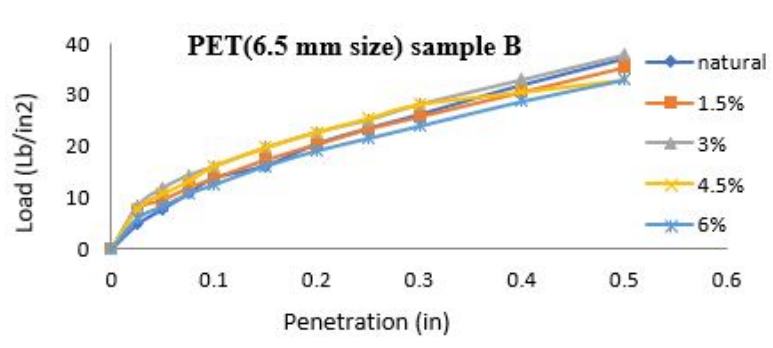

Figure 5: Percentage of PET (6.5 mm), Sample B, Penetration versus Load.

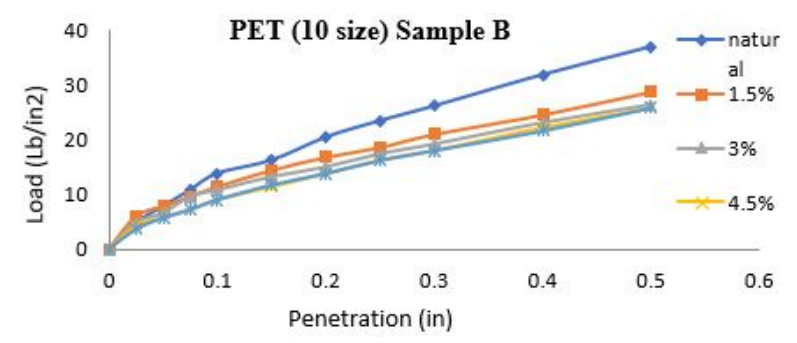

Figure 6: Penetration versus Load, Percentage of PET (10 mm), Sample B. 
Citation: Eltayeb JEI, Awadelkareem A (2018) Utilization of Waste Plastic in Soil Backfill. J Environ Anal Chem 5: 246. doi:

Page 4 of 5

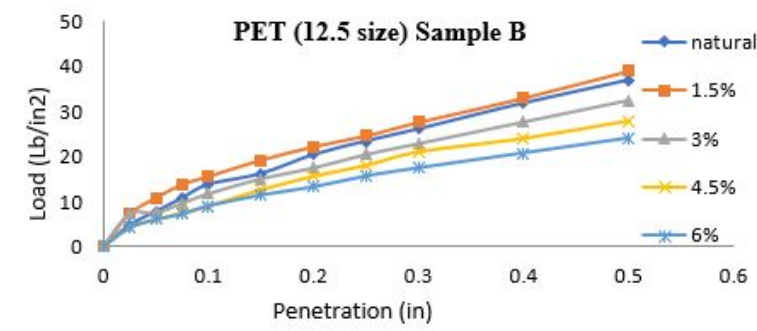

Figure 7: Penetration versus Load, PET (12.5 mm), Sample B.

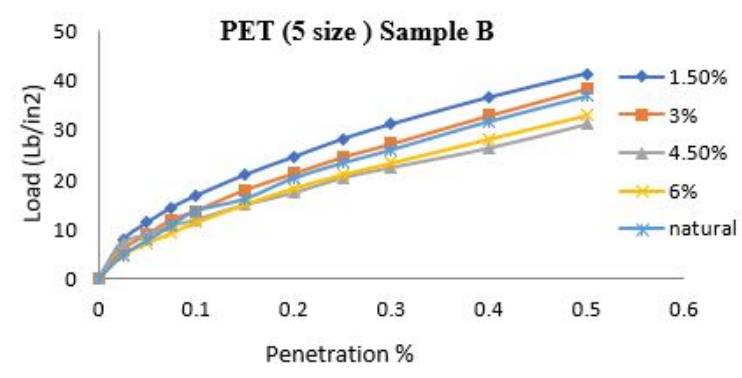

Figure 8: Penetrations versus Load, PET (5 mm), Sample B.

\begin{tabular}{|c|c|c|c|c|c|c|c|}
\hline \multirow{2}{*}{$\begin{array}{l}\text { Percentage } \\
\text { chips }\end{array}$} & \multicolumn{5}{|c|}{ CBR for size of chips PET } & \multicolumn{2}{|l|}{ CBR } \\
\hline & $\begin{array}{l}\text { natura } \\
1\end{array}$ & 5 & 6.5 & 10 & 12.5 & $\underset{m}{\operatorname{minimu}}$ & $\begin{array}{l}\text { maximu } \\
\mathrm{m}\end{array}$ \\
\hline $0 \%$ & 1.38 & 1.38 & 1.38 & 1.38 & 1.38 & 1.38 & 1.38 \\
\hline $1.50 \%$ & - & 1.68 & 1.38 & 1.14 & 1.56 & 1.14 & 1.68 \\
\hline $3 \%$ & - & 1.42 & 1.62 & 1.08 & 1.17 & 1.08 & 1.62 \\
\hline 4.55 & - & 1.2 & 1.62 & 0.92 & 1.04 & 0.92 & 1.62 \\
\hline $6 \%$ & - & 0.9 & 1.28 & 0.92 & 0.9 & 0.9 & 1.28 \\
\hline minimum & \multirow{2}{*}{ CBR } & 0.9 & 1.28 & 0.92 & 0.9 & 0.9 & 1.28 \\
\hline maximum & & 1.68 & 1.62 & 1.38 & 1.56 & 1.38 & 1.68 \\
\hline
\end{tabular}

Table 6: CBR for Different Sizes and Percentages of PET, Sample B.

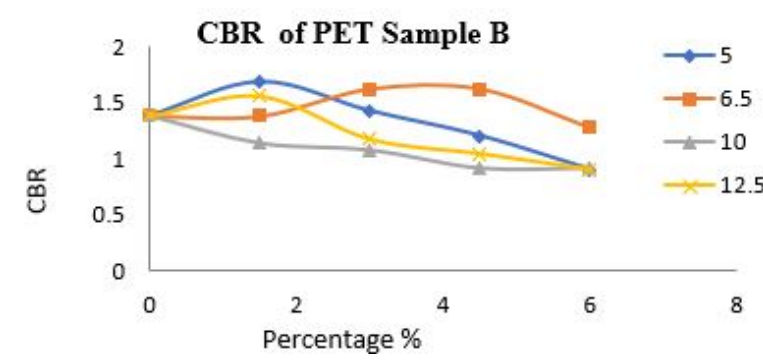

Figure 9: Percentage of PET versus CBR in Different Size, Sample B.

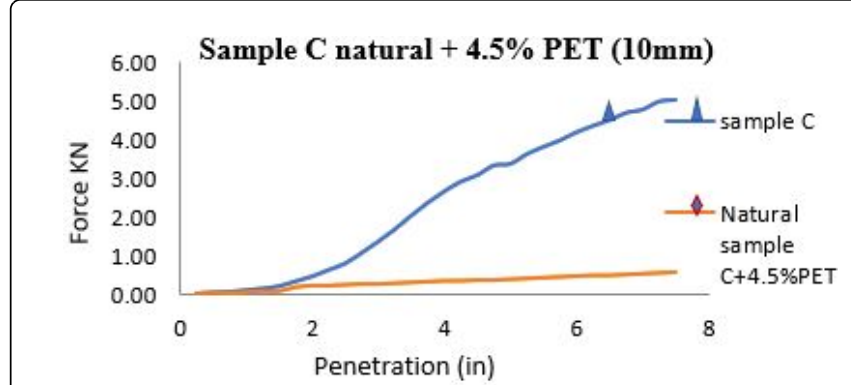

Figure 10: Penetrations versus Load, Sample C, Natural and Soil $+4.5 \%$ PET $(10 \mathrm{~mm})$.

\begin{tabular}{|l|l|}
\hline Type of sample & CBR \\
\hline Sample C natural & 16.64 \\
\hline Sample C (natural+4.5\% PET $(10 \mathrm{~mm})$ & 2 \\
\hline
\end{tabular}

Table 7: CBR Tests for Different Samples.

\section{Conclusion}

The influence of waste plastic chips on soil samples were studied by conducting tests with various percentages of waste plastic chips and different sizes. The following conclusions were drawn.

It is clear that mixing waste plastic chips in soil sub grade cannot increase soil strength because soil sample without the waste plastic chips has larger strength than those with waste plastic chips. The waste plastic chips reduce the maximum dry unit weight of soil-sub grade and optimum moisture content which is a good evidence of poor soil properties. CBR values are increased when percentage content of waste plastic chips is $1.5 \%$ (size 5, and $12.5 \mathrm{~mm}$ ) and $3 \%, 4.5 \%$ (size $6.5 \mathrm{~mm}$ ) in sample B, but just $3 \%$ decrease in sample $A$, the values decreases after addition of plastic in sample C. the CBR values obtained for subgrade, sub base and base range $0.9 \%$ to $1.68 \%$. The values are below such as $3-30 \%$ and $30-85 \%$ and $98 \%$, those required by British standard Figures. Hence, addition of waste plastic to soil did not improve the properties. The reason for these findings may be attributed to the creation of voids between soil particles and plastic chips. The soil sub grade with PET did not increase soil strength because of the decrease of cohesion compared to the results of the pure natural soil under consideration.

\section{Recommendation}

In order to use plastic waste in soil improvement for engineering projects, binders can be used to increase cohesion and fill the voids.

\section{References}

1. James DMT (2009) Introduction to Plastic Recycling. Jaban: Plastic Waste Management Institution.

2. Richard C (2004) Biodegradability and Degradability of Plastic Waste. Washington : International Solid Waste Association.

3. Chen DM (2007) Creep Behavior of Recycled Plastic Lumber in Slope Stabilization Applications. Journal of Material in Civil Engineering 19: 130-138. 
Citation: Eltayeb JEl, Awadelkareem A (2018) Utilization of Waste Plastic in Soil Backfill. J Environ Anal Chem 5: 246. doi: $10.4172 / 2380-2391.1000246$

Page 5 of 5

4. Choudhary AK, Jha JN Gil KS (2014) Utilization of Plastic Wastes for Improving the Sub-grades in Flexible Pavements. Paving Materials and Pavement Analysis, pp: 320-326.

5. Khane FH (2016) Analysis of the Influence of Waste Polymer on Soil Sub grade. International Research Journal of Engineering and Technology 3: 1810-1817.
6. Sivakumar-Babu GL, Jaladurgamand-Raja ME (2014) Strength and Deformation Characteristics of Fly Ash Mixed with Randomly Distributed Plastic Waste. J Mater Civ Eng J Mater Civ Eng 26: 1-7.

7. Edil TB, Soleimanbeigi A (2015) Compressibility of Recycled Materials for Use as Highway Embankment Fill. J Geotech Geoenviron Eng 5: 1-13. 